\title{
thoughts and comment
}

\section{Perinatal Loss: Socioeconomic Factors}

WINNIE WILLIS, RN, BA, MEd, MS

The author concludes that advances in the technology of medical care to women in their reproductive years have outstripped the progress toward elimination of factors which place mothers at social risk. Maternal and child health professionals must become actively involved in the development of legislation and policies which address the relationship between socioeconomics and reproductive risk.
For the purposes of this presentation, socioeconomic factors are defined as those factors, such as social class, income, education, and marital status, which dictate life-style and influence participation in social institutions. All are interdependent. They determine where an individual will live, his/her access to a variety of services, as well as family values and attitudes. Also, the concept of race is historically linked to socioeconomic status.

The first published study to substantiate the relationship between socioeconomic conditions and pregnancy outcome was the 1925 Children's Bureau Survey "Causal Factors in Infant Mortality." Its findings showed that a) color and nationality exerted a "powerful" influence over infant mortality, b) mortality a mong infants in congested living conditions was $2 \frac{1 / 2}{2}$ times as high as among infants living in noncongested homes, and c) there was a marked correlation between a father with low earnings and high infant mortality-this relationship being independent of nationality and largely independent of housing congestion. In short, minority color and nationality, congested living space, and a father with low earnings were seen as interdependent factors which described a quality of life incompatible with basic good health and access to health care during the reproductive cycle.

Dr. Ella Oppenheimer, on request of the Children's Bureau, surveyed infant mortality in Memphis for the years 1930 to 1932 . She found that the areas of the city with the poorest housing, which happened to be inhabited by blacks, had the highest infant mortality rate. The rate for blacks was 180 mortalities per 1,000 live births as compared to $80 / 1,000$ among whites. ${ }^{1}$ She stated at the conclusion of her study, "It is well recognized that neither health services for prevention of disease, nor medical services for its treatment, can function efficiently if underlying basic necessities are lacking or inadequate."' The 1938 Children's Bureau Conference on Better Care for Mothers and Babies was a restatement of the problem of inadequate medical care to low-income groups.

From these early beginnings we move to the classic, British Perinatal Mortality Studies of $1958 .^{2}$ Involving 25,000 women, they stand as the earliest, most comprehensive, and most predictive surveys undertaken on a national scale. In these studies the factors of maternal age, parity, and social class (as determined by husband's occupation) had considerable influence on mortality rates. Among the married sample, the age at first pregnancy and the number of pregnancies were found to be related to the husband's occupation. For example, the wife of a profes- 
sional man represented a lower perinatal mortality rate group because she was more likely to be in the optimum childbearing years-though some were older, these women had access to reproductive health care, were more likely to value limitation of family size, and both the women and their husbands originated from backgrounds with more economic advantages, which maximized growth potential and physical development.

At the other end of the social spectrum, the wife of the unskilled worker was found to represent the highest mortality rate group. She usually fell at the age extremes of the reproductive experience, she had severely limited access to reproductive health care, limitation of family size was less likely to occur, and she usually originated from an economic environment which was hostile to the achievement of her full potential for growth.

Marital status was another highly significant influence on mortality rate. The rate for unmarried mothers was twice as high as that for married women with the most advantages. It was .09\% higher than the least advantaged married women and 50 to $60 \%$ greater than the population aggregate. ${ }^{2}$ Since medical risk for this group was not found to be inconsistent with that of married mothers in age-specific categories, social factors are strongly implicated. Of additional interest, however, was the fact that the HEW-sponsored Collaborative Perinatal Study, conducted in several American cities from 1959 to 1965, did not support this finding among unmarried mothers. ${ }^{3}$ It was the first largescale report in the history of perinatal mortality surveys which reported divergent outcomes on this issue.

The British study further showed that geography and socioeconomics were interdependent and related to the perinatal mortality rate. Rural mothers had a higher perinatal mortality rate than urban mothers. Speculations about possible reasons for these results included a) a higher percent of the rural population is poor, b) there are fewer available services in rural areas, and c) poverty has a direct influence on access to service and education. However, poor populations, whether rural or urban, were similar in their isolation from health care.

The Collaborative Perinatal Study, briefly referred to above, also called "The Women and Their Pregnancies," presented a wealth of information relative to the social epidemiology of perinatal outcome. For example, the maternal ages of 18 and 19 years were shown to be the years of optimum perinatal outcome. Overall perinatal mortality for age categories below 20 years was not particularly high even though the
"In short, minority color and nationality, congested living space, and a father with low earnings were seen as interdependent factors which described a quality of life incompatible with basic good health and access to health care during the reproductive cycle."

"We are not lacking in the technology to prevent and combat perinatal loss. ... . Our difficulty arises in the application of that technology to people whose means, backgrounds, motivations, attitudes, and habits cannot be standardized." 
"Within the existing health care system we can deliver better and more comprehensive services to childbearing women through increased use of interdisciplinary teams." age group of 15 years and under did have the highest risk of delivering low-birthweight babies. A consistent relationship was shown between race and adverse fetal outcome. There were higher perinatal mortality rates and a higher incidence of low birthweight among blacks. ${ }^{3}$

This same relationship was found in 1968 in a study of 140,000 live births in New York City. There were 35.7 deaths per 1,000 live births among black infants as compared to 15.2/1,000 among white infants. Almost three-fourths of black native-born mothers are at some risk during pregnancy compared to one-third of white native-born mothers. ${ }^{4}$

Also of significant import among blacks was shorter mean gestational age, later registration for prenatal care, and fewer prenatal visits.

At this point, we as health professionals, must confront these social and economic issues, the embodiment of which may be the outspoken patient who says, "If it wasn't for me, you wouldn't have a job."

We are not lacking in the technology to prevent and combat perinatal loss, e.g., sonography, the L/S ratio, CPAP, and the broad concept of regionalization, to name a few. Our difficulty arises in the application of that technology to people whose means, backgrounds, motivations, attitudes, and habits cannot be standardized. Within the existing health care system we can deliver better and more comprehensive services to childbearing women through increased use of interdisciplinary teams. Comprehensive care requires a variety of skills and a larger investment of total time in the solution of the multiple problems of low-income families.

The prenatal visit still stands as the most decisive factor in the care of the mother at risk. More than ever the structure of the prenatal visit must be responsive to the needs of disadvantaged populations who, because of their everyday struggle for survival, will not partake of anything that does not show some personal, immediate, and concrete gains.

Where other team members are available, a woman need not be scheduled to see the physician at every prenatal visit; perhaps she could see the nurse instead. In a large clinic setting, visits to see the nutritionist or the health educator, or a home visit by the public.health nurse may be scheduled alternately with physician visits.

Of immediate importance is the need to change the content of all visits so that no matter in what setting they occur, they will include formal, allotted time for patient education, and the mother should know in advance to expect this. Prenatal education will not change a woman's socioeconomic status, but it will provide her with a body of health knowledge, including available services, and it will have a positive influence on her attitude toward health care and health professionals.

In a 1966 study at Boston City Hospital, Dr. Elizabeth Watkins investigated the factors which stimulate low-income mothers to seek prenatal care. Her study showed that the decision was influenced by knowledge of medical resources and impressions of how these resources would meet their needs.

As illustrated by the maternity and infant care projects and the children and youth projects, informed, participating clients begin to incorporate attitudes and habits which support the individual's personal responsibility for his/her state of health.

According to the New York City Study, ${ }^{5}$ it is possible to identify $95 \%$ of mothers at risk utilizing an index of social, medical, and sociomedical criteria. Establishment of a registry of pregnant women at risk is therefore feasible within the existing system. Public health nurses, and where available, family health workers, are prime resources.

As health professionals, we can a) add our support to encourage the continuation of funding for maternity and infant care projects because of their service to low-income mothers, b) support the broadening of 
maternity and newborn care coverage in hospitalization insurance plans so that medically indigent families and those not covered by Medicaid can have access to care, c) tune in to health and social legislation so that our personal and professional views can be heard, and d) maintain a liaison with educational, legal, and social and welfare groups; as a constituency of symbiotic, interdisciplinary groups, we can work together as advocates for and executors of comprehensive care to high-risk families.

\section{Acknowledgments}

Adapted from a presentation at the 13th Annual Michigan Conference on Maternal and Perinatal Health, Grand Rapids, Michigan, March 1974.

\section{References}

1. Oppenheimer, E.: "Infant Mortality in Memphis." Washington, D.C., U.S. Children's Bureau, Publication \#233, 1937, pp 37, 39

2. Butler, N., and D. Bonham: Perinatal Mortality: The First Report of the 1958 British Perinatal Mortality Survey. Edinburgh and London, E. S. Livingston Ltd., 1963, p 20

3. Niswander, K., M. Gordon, et al.: The Collaborative Perinatal Study of the National Institute of Neurological Diseases and Stroke: The Women and Their Pregnancies. Washington, D.C., U.S. National Institutes of Health, DHEW Publication \#(NIH) 73-379, 1972, p 58

4. Institute of Medicine, National Academy of Sciences: Infant Death: An Analysis by Maternal Risk and Health Care. Washington, D.C., 1973, p 3

5. Kohl, S.: Perinatal Mortality in New York City. Cambridge, Mass., Harvard University Press, 1955

\section{Supplemental Bibliography}

Butler, N., and E. Alberman: Perintal Problems: The Second Report of the 1958 British Perinatal Mortality Survey. Edinburgh and London, E.S. Livingston Ltd., 1969

Health Planning Advisory Council and the Office of Health and Medical Affairs: Perinatal Intensive Care in Michigan: A Statement of Public Policy. Lansing, Michigan, 1973

Proceedings of Conference on Better Care for Mothers and Babies, Washington, D.C., Children's Bureau Publication \#246, 1938

Woodbury, R. M.: Causal Factors in Infant Mortality: A Statistical Study Based on Eight Cities. Washington, D.C., Children's Bureau Publication \#142, 1925

Address reprint requests to Winnie Willis, RN, Maternal and Child Health, School of Public Health, University of Michigan, Ann Arbor, MI 48104.

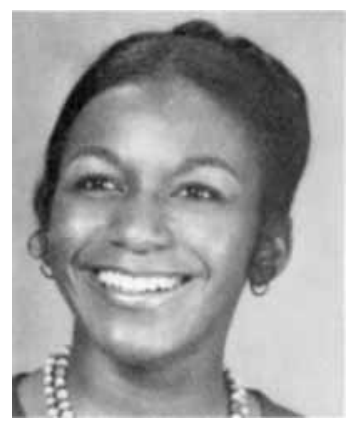

Winnie Willis is Assistant Professor of Maternal and Child Health and Public Health Nursing at the University of Michigan School of Public Health in Ann Arbor. She received her MEd from Boston University and her MS in Maternal and Child Health from the School of Public Health at Harvard. Ms. Willis is a member of ANA, NLN, the American Public Health Association, and the Association of Teachers of Maternal and Child Health.

\section{Paychoprophylaxis in Obstotrice}

The Long Island Chapter of the American Soclety for Psychoprophylaxis in Obstetrics will host an educational seminar on Saturday, May 14, at Colonie Hill, Hanppange (Long Island), New York. Featured speakers will be Carol Blair and Elizabeth Salerno, authors of The Expanding Family, Childbearing, who will speak on the psychosocial aspects of pregnancy. Registration is $\$ 15$, which includes lunch. For preregistration or further information, contact C. Meyer, RN, PO Box 186, Bohemia, NY 11716. 